\title{
O desenho e a escrita como elementos para o desenvolvimento da alfabetização científica: análise das produções dos estudantes de um clube de ciências
}

Willa Nayana Corrêa Almeida willa.almeida@hotmail.com orcid.org/0000-0002-1449-9266 Universidade Federal do Pará (UFPA),
Castanhal, Pará, Brasil

Josiane Lima de Amorim josianedpd19@hotmail.com orcid.org/0000-0001-8327-9147 Universidade Federal do Pará (UFPA), Castanhal, Pará, Brasil

João Manoel da Silva Malheiro joaomalheiro@ufpa.br orcid.org/0000-0002-2495-7806 Universidade Federal do Pará (UFPA), Castanhal, Pará, Brasil

\section{RESUMO}

Este estudo objetiva analisar os indicadores de Alfabetização Científica evidenciados nas produções de desenho e escrita desenvolvidos por estudantes do Clube de Ciências Prof. Dr. Cristovam W. P. Diniz, durante uma atividade experimental investigativa. A investigação está fundamentada em uma abordagem qualitativa, sendo utilizada a Análise de Conteúdo para interpretação de 31 registros. O espaço analisado é considerado um ambiente não formal destinado ao ensino, pesquisa e extensão de ações didáticas voltadas às Ciências e Matemáticas. A atividade experimental investigativa aplicada foi intitulada "Problema da Água que não Derrama" e explorou propriedades ligadas à tensão superficial da água. A partir da análise dos registros, conseguimos compreender como os estudantes constroem e expõem o conhecimento científico envolvido na sequência de ensino investigativo, explorando o problema proposto, os materiais utilizados, a organização e raciocínio de ideias a cada etapa da atividade, bem como as explicações a aproximações com cotidiano do fenômeno envolvido no experimento. Os indicadores de Alfabetização Científica evidenciados foram a seriação, organização e classificação de informações, assim como o raciocínio lógico e proporcional, justificativa, previsão e explicação. Assim, compreendemos que as duas formas de linguagem colaboram para que estudantes consigam compreender e discutir a Ciência de maneira consciente e reflexiva, engajando-os no processo de Alfabetização Científica.

PALAVRAS-CHAVE: Alfabetização Científica. Escrita. Desenho. Clube de Ciências. 


\section{INTRODUÇÃO}

$\mathrm{Na}$ educação em Ciências, as formas mais tradicionais para se transmitir as ideias são as linguagens oral e escrita, entretanto, o uso de outros recursos semióticos como as imagens e desenhos é cada vez mais explorado em sala de aula, "a fim de tornar mais completa uma ideia a ser apresentada" (SASSERON; CARVALHO, 2010, p. 2).

Conforme Oliveira e Carvalho (2005), a escrita de textos nas aulas de Ciências tem se consolidado como importante ferramenta para a criação de um sistema conceitual coerente, se destacando como um mecanismo cognitivo que organiza e refina ideias sobre um tema específico. Já os desenhos se configuram como parte integrante da construção e comunicação dos conceitos científicos, pois facilita a explicação de pensamentos e promove o compartilhamento de significados entre os pares (CAPPELLE; MUNFORD, 2015).

A utilização desses recursos pelos alunos pode representar aspectos da interação com a realidade por eles conceituada, fazendo com que a aprendizagem se constitua a partir da "internalização dos processos compartilhados no plano social da sala de aula, em que a linguagem e outros modos semióticos, como o desenho, atuam como ferramentas mediadoras centrais na construção do conhecimento sobre a Ciência" (CAPPELLE; MUNFORD, 2015, p. 128).

Esse processo de aquisição e comunicação dos conceitos possibilita a Alfabetização Científica dos alunos, que pode ser definida como o domínio da linguagem da Ciência, visando a formação dos sujeitos para atuarem na sociedade de maneira crítica e reflexiva (CAPELLE; MUNFORD, 2015). Para Sasseron (2008), a Alfabetização Científica pode ser verificada por meio de indicadores que têm a função de mostrar algumas destrezas que devem ser trabalhadas pelos estudantes quando se deseja construir a educação sobre as Ciências.

Estes indicadores se caracterizam em habilidades relacionadas ao fazer científico e são

competências comuns desenvolvidas e utilizadas para a resolução, discussão e divulgação de problemas em quaisquer das Ciências quando se dá a busca por relações entre o que se vê do problema investigado e as construções mentais que levem ao entendimento dele (SASSERON; CARVALHO, 2010, p. 4).

Quando o professor almeja trabalhar a Alfabetização Científica em sua sala de aula, o mesmo deverá estimular em seus alunos essas destrezas, para possibilitar que eles construam respostas consistentes para explicar fenômenos e solucionar problemas. Assim, entendemos que o ensino de Ciências pode ser mediado por atividades experimentais investigativas, de maneira que incitem os alunos a mobilizarem seus conhecimentos e contribuindo para uma melhor compreensão dos conceitos envolvidos (ALMEIDA, 2017).

Neste aspecto, consideramos relevante aproximar a Alfabetização Científica desenvolvida em sala de aula, com o ensino de Ciências promovido em espaços não formais, tais como os Clubes de Ciências. Gohn (2001) concebe que a educação não formal aborda processos educativos que ocorrem fora das unidades escolares formais, sendo organizada pela sociedade civil ou por instituições de ensino básico ou superior em parceria com a comunidade. 
A concepção de educação não formal de Gonzaga et al. (2019) se aproxima da visão de Gohn, no sentido de envolver sujeitos conscientes de seu papel na sociedade, em que nesses espaços devem ser desenvolvidas atividades dinâmicas que visem fugir daquelas rotineiramente propostas no espaço da sala de aula formal e que discutam temas que envolvam o contexto do estudante.

Com relação aos Clubes de Ciências, autores consideram que, apesar de existirem diferentes definições e tipos, parece consensual que esses espaços se caracterizam por um ambiente educacional, constituído por estudantes curiosos acompanhados de professores, que se reúnem regularmente em torno de temas, atividades ou problemas específicos (BUCH; SCHROEDER, 2013; PRÁ; TOMIO, 2014; TOMIO; HERMANN, 2019).

Neste aspecto, estudantes desenvolvem, com orientação de um educador, projetos investigativos, culturais, de expressão e cooperação, contribuindo para elaboração de conhecimentos e ampliação dos seus estilos de pensamento, bem como a indagação e o estabelecimento de relações cada vez mais complexas no mundo (BUCH; SCHROEDER, 2013; TOMIO; HERMANN, 2019).

Apesar de alguns Clubes de Ciências acontecerem em interfaces do ensino formal, a maioria ocorre em contextos da educação não formal, os quais buscam "romper com a forma tradicional de organização dos tempos e espaços destinados convencionalmente pelas escolas" (TOMIO; HERMANN, 2019, p. 3).

Nessa perspectiva, o Clube de Ciências Prof. Dr. Cristovam W. P. Diniz na Universidade Federal do Pará - Campus de Castanhal surge como um ambiente não formal de ensino de Ciências e Matemática que busca promover uma aprendizagem significativa a partir da utilização de variadas formas de linguagem. Para isso, adota uma proposta pedagógica construtivista e interdisciplinar de educação, em que os professores fazem uso de atividades experimentais investigativas compostas de sete etapas específicas (MALHEIRO, 2016).

Tendo em vista esse cenário, objetivamos analisar os indicadores de Alfabetização Científica evidenciados nas produções de desenho e escrita desenvolvidos por estudantes do Clube de Ciências Prof. Dr. Cristovam W. P. Diniz, durante uma atividade experimental investigativa.

\section{A ESCRITA E O DESENHO NA ALFABETIZAÇÃO CIENTÍFICA}

Escrever e desenhar são recursos que promovem a construção de conhecimentos científicos. Nesse sentido, essas ações podem ser vistas como uma forma de linguagem na qual se expressam pensamentos, ideias e falas, para auxiliar o indivíduo na formação de significados.

Conforme Soares (2004), a escrita consiste na utilização de um sistema alfabético e ortográfico que se origina e configura a partir de práticas sociais que um indivíduo adquire e utiliza ao longa de sua vida. Para Sasseron (2008), a escrita e a leitura são meios pelo qual o indivíduo pode expor situações e/ou sistematizar conhecimentos, promovendo a construção de conceitos necessários para o cidadão desenvolver-se na vida diária. A autora discute ainda sobre a importância do ato de escrever nas aulas de Ciências, uma vez que "um texto escrito traz consigo muitos dos elementos do fazer científico" (SASSERON, 2008, p. 67). 
Nesse aspecto, entendemos a escrita como uma importante ferramenta para a criação de um sistema conceitual coerente, em que tem se destacado como um mecanismo cognitivo que organiza e refina ideias sobre um determinado tema (OLIVEIRA; CARVALHO, 2005).

O desenho é outra forma de linguagem de exposição de ideias que favorece a aprendizagem. Logo, sua importância no desenvolvimento da criança é enfatizada no processo de alfabetização, pois colabora para a formação do sujeito. "O desenho traz em seu conteúdo a expressão do pensar e do sentir do indivíduo. $\mathrm{E}$ na criança, tem o significado da expressão do seu desenvolvimento motor e aquisições do seu relacionamento com o meio social" (FERREIRA, 2015, p. 2).

A esse respeito, Carvalho e Sasseron (2010, p. 17) ressaltam que "o desenho atua como uma forma auxiliar na exposição dos significados por eles construídos sobre aquele assunto em específico, reforçando afirmações feitas ou complementando o significado daquelas ideias que ainda não conseguem ser explicitadas em um texto escrito".

No ensino de Ciências, Kundlatsch e Silva (2016) destacam que o ato de desenhar melhora o engajamento e a motivação dos alunos, promovendo a compreensão da Ciência. Além disso, as autoras mencionam que a apropriação de novos saberes pode ser admitida pelo desenho, já que a aprendizagem acontece por meio da assimilação e reconstrução de conteúdos, e de como cada pessoa os organiza de maneira criativa.

Entretanto, o desenho muitas vezes sozinho não contempla todo o sentido ou significado de um conceito, por isso há a necessidade da linguagem escrita para complementá-lo. Dessa forma, faz-se necessária a combinação entre esses diferentes recursos semióticos para coordenação de ideias mais coesas e coerentes, "cada qual acrescentando detalhes que enriquecerão a percepção que se tem sobre tal assunto, permitindo, portanto que se construa uma ideia mais bem sistematizada daquilo que se discute" (SASSERON; CARVALHO, 2010, p. 7).

Desta maneira, compreendemos que as utilizações desses dois elementos linguísticos oportunizam que alunos explicitem as informações que pretendem transmitir, em que a escrita auxilia e/ou complementa as ideias já apresentadas nos desenhos e vice-versa.

Para que isso ocorra, cabe ao docente desenvolver uma prática que considere esses recursos a favor de suas técnicas de ensino e aprendizagem. Nas aulas de Ciências tem-se discutido cada vez mais a necessidade de se trabalhar os conteúdos de maneira diferenciada, na qual o professor ofereça oportunidades de discussão e reflexão sobre os conceitos, levando os alunos a construírem suas próprias conclusões sobre determinados conteúdos.

Cappelle e Munford (2015) destacam que a educação científica visa permitir que os alunos sejam capazes de utilizar de maneira significativa e adequada as formas de representação e comunicação, "integrando funcionalmente a linguagem verbal, as expressões matemáticas, as representações visuais, as ações, dentre outras, na construção de significados" (p. 128).

Portanto, destacamos a importância de o professor modificar sua metodologia de ensino com a finalidade de habilitar o estudante na construção de ideias e significados para resolução de problemas ou questões que envolvam temas 
científicos. Além disso, o docente deve usufruir de recursos e métodos que possibilitem ao aluno adentrar no campo do ensino investigativo de maneira ativa (SASSERON; CARVALHO, 2010).

Nessa perspectiva, podemos afirmar que o processo de Alfabetização Científica pode ser visualizado em uma sala de aula, haja vista que se desenvolve a partir da promoção de atividades didáticas que envolvem os alunos em situações problemas acerca de sua realidade e sobre diversas temáticas científicas, no intuito de explorar discussões que promovam a construção do conhecimento científico (SASSERON, 2008; SASSERON; CARVALHO, 2010).

Conforme Sasseron (2008), existe um debate sobre a complexidade do conceito Alfabetização Científica, uma vez que essa expressão é apresentada sob diversas nomenclaturas, tais como Enculturação Científica e Letramento Científico. Sobre esse último, Cunha $(2017,2018)$ consideram que o termo Letramento Científico é o mais adequado, uma vez que considera a ciência como uma das formas de ver e compreender o mundo, sendo uma contribuição cultural que possui seus próprios valores. Nesse aspecto, o "letramento científico enfoca as práticas sociais de uso do conhecimento científico, tanto em termos práticos quanto cívicos, no exercício da cidadania na vida cotidiana" (CUNHA, 2018, p. 38).

No entanto, Cunha $(2017,2018)$ também destacam que o termo Alfabetização Científica é o mais utilizado em pesquisas ligadas ao ensino de Ciências no Brasil, nas quais se baseiam nas ideias de Attico Chassot, que defende que a educação científica seja revista, fugindo da memorização de conceitos que só geram a antipatia e o desinteresse dos estudantes.

No sentido contrário, devem ser valorizados e criados momentos de interação em torno de propostas educacionais significativas, que contribuem para uma melhor compreensão do conhecimento científico e do mundo em que o estudante está inserido. Assim, o autor defende que "ser alfabetizado cientificamente é saber ler a linguagem em que está escrita a natureza. É um analfabeto científico aquele incapaz de uma leitura do universo" (CHASSOT, 2003, p. 91).

Assim, entendemos que, apesar dessas diferenças no designo dos termos, seus objetivos visam alcançar os mesmos pressupostos no ensino de Ciências, pois buscam uma formação cidadã dos indivíduos para que dominem os conhecimentos e habilidades para lidarem com questões da sociedade, tecnologia e meio ambiente. Com isso, optamos em utilizar somente o termo Alfabetização Científica.

Sasseron e Carvalho (2011) explica que a Alfabetização Científica deve desenvolver nos alunos a capacidade de organizar seu pensamento de maneira lógica, auxiliando na construção de uma consciência mais crítica em relação ao mundo. Sendo que, para alcançá-la no Ensino Fundamental, deve-se incentivar o trabalho coletivo entre os discentes, enfatizando atividades investigativas que os levem a apresentar, argumentar e discutir os temas que são tratados em sala.

Autores como Chassot (2003), Sasseron (2008), Carvalho et al. (2009), Carvalho e Sasseron (2010), Cappelle e Munford (2015), Kundlatsch e Silva (2016), Malheiro (2016) e Moraes e Carvalho (2017) ressaltam a importância de um ensino que promova uma aprendizagem significativa por meio de metodologias que integrem escrita e desenho, contribuindo para a Alfabetização Científica. 
Carvalho et al. (2009) apresentam o ensino por investigação como uma oportunidade para que o aluno possa observar, manipular e refletir sobre aquilo que está sendo proposto pelo professor em sala de aula. O trabalho prático faz com que o estudante verifique conceitos.

Nesse sentido, para que seja desenvolvido um trabalho na perspectiva da Alfabetização Científica em sala, é necessário que sejam feitas sequências didáticas investigativas. Por meio das discussões, argumentações e/ou produções escritas e gráficas os alunos podem demonstrar se de fato está sendo construído o conhecimento científico (SASSERON; CARVALHO, 2010).

No que se refere às habilidades e competências que devem ser utilizadas pelos alunos durante a construção de conhecimentos em atividades científicas, Sasseron (2008) e Sasseron e Carvalho (2010) apresentam indicadores que possuem a função de mostrar algumas destrezas que devem ser trabalhadas quando se deseja construir a Alfabetização Científica.

Nas atividades científicas os alunos irão utilizar diferentes indicadores para alcançar os objetivos e resultados conforme as tarefas a serem resolvidas. Assim, os indicadores são organizados em três grupos, que são acionados e colocados em prática quando há necessidade de resolver um problema. Evidenciamos na Figura 1 os indicadores de Alfabetização Científica apresentados por Sasseron (2008) e Sasseron e Carvalho (2010).

Figura 1 - Esquema de representação dos indicadores de Alfabetização Científica

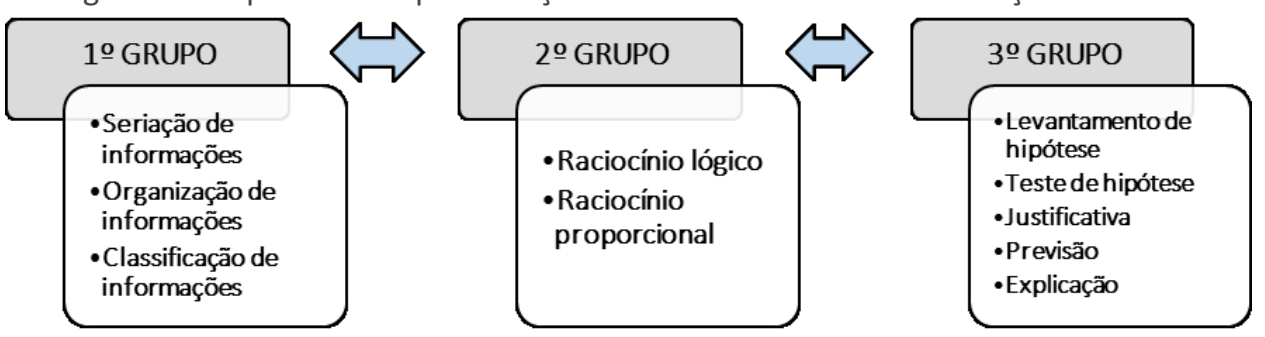

Fonte: Adaptado de Sasseron (2008) e Sasseron e Carvalho (2010).

Fazem parte do primeiro grupo os indicadores organizar, classificar e seriar informações, estando ligados ao trabalho com os dados empíricos ou com as bases por meio das quais se compreende um assunto ou situação.

Para Sasseron (2008, p. 67), a seriação de informações está relacionada ao "estabelecimento de bases para a ação investigativa. Não prevê, necessariamente, uma ordem que deva ser estabelecida para as informações: pode ser uma lista ou uma relação dos dados trabalhados ou com os quais se vá trabalhar".

Sasseron e Carvalho (2010) enfatizam que a organização de informações surge quando se procura preparar os dados existentes sobre o problema investigado e "ocorre nos momentos em que se discute sobre o modo como um trabalho foi realizado. Este indicador pode ser vislumbrado quando se busca mostrar um arranjo para informações novas ou já elencado anteriormente" (p. 4).

Em relação à classificação de informações, as autoras destacam que este momento acontece no intuito de constituir hierarquicamente categorias dos dados alcançados, buscando também ordenar os elementos na procura de semelhanças entre os mesmos. Logo, esse indicador caracteriza-se por ser voltado para a ordenação dos elementos com os quais se trabalha (SASSERON; CARVALHO, 2010). 
O segundo grupo de indicadores engloba o raciocínio lógico e raciocínio proporcional, que se relacionam a estruturação do pensamento que molda as afirmações feitas durante as aulas.

Nesse sentido, o raciocínio lógico abrange as dimensões estruturais e organização das ideias do pensamento e as falas. Então, este indicador compreende o modo com as ideias são expostas (SASSERON; CARVALHO, 2010). Já o raciocínio proporcional "dá conta de mostrar como se estrutura o pensamento, e refere-se também à maneira como variáveis têm relações entre si, ilustrando a interdependência que pode existir entre elas" (SASSERON, 2008, p. 67-68).

No terceiro grupo estão os indicadores levantamento e teste de hipótese, justificativa, previsão e explicação, que podem surgir nas etapas finais das discussões, caracterizando-se na busca pela compreensão de fatos.

Conforme Sasseron (2008), no levantamento de hipótese é registrado momentos em que se alcançam suposições referentes a certo tema, podendo ser afirmações ou perguntas. $O$ teste de hipótese relaciona-se com as etapas em que as suposições levantadas anteriormente são testadas, podendo acontecer tanto por meio da manipulação de objetos, quanto no campo das ideias.

A justificativa aparece quando em uma afirmação qualquer proferida lança-se mão de uma garantia para o que é proposto; isso faz com que a afirmação ganhe aval, tornando-a mais segura. 0 indicador da previsão é evidenciado quando se afirma uma ação e/ou fenômeno que sucede associado a certos acontecimentos (SASSERON, 2008).

A explicação surge quando se busca relacionar informações e hipóteses já levantadas, apresentando uma explanação sobre o que foi observado. Conforme Sasseron (2008), quando essa afirmativa é bem estruturada deve permitir a percepção de relações entre os fenômenos do mundo natural e o trabalho do homem sobre ele. Isso promove "a construção de modelo explicativo capaz de tornar claro a compreensão que se tem de um problema qualquer e as relações que se pode construir entre este conhecimento e outras esferas da ação humana" (SASSERON, 2008, p. 69).

Sasseron e Carvalho (2010) também destacam que nas discussões em salas de aula podem surgir vários indicadores ao mesmo tempo que podem até mesmo dar suporte com o intuito de complementar as ideias fomentadas. Deste modo, os indicadores de cada grupo podem surgir de maneira aleatória, não ocorrendo em sequência, uma vez que os alunos podem fazer uso de qualquer habilidade dependendo da situação problema na qual estejam engajados.

Nessa perspectiva, entendemos que esses indicadores se configuram como um relevante eixo de análise da Alfabetização Científica evidenciada nos escritos e desenhos desenvolvidos por estudantes durante uma atividade experimental investigativa de um Clube de Ciências.

\section{ASPECTOS METODOLÓGICOS}

Esta pesquisa está fundamentada em uma abordagem qualitativa, uma vez que busca compreender as ações e a fala dos participantes, levando em consideração suas opiniões e princípios, o que possibilita uma maior averiguação 
descritiva dos fatos. Conforme Oliveira (2014, p. 37), esse tipo de investigação consiste em "um processo de reflexão e análise da realidade através da utilização de métodos e técnicas para compreensão detalhada de um objeto de estudo em seu contexto histórico e/ou segundo sua estruturação".

Quanto aos procedimentos, este trabalho enquadra-se em uma pesquisa documental. Oliveira (2014) ressalta que esse enquadramento tem como fonte documentos no sentido amplo, tais como jornais, fotos, imagens, filmes, gravações, documentos legais, textos, entre outros, que ainda não receberam nenhum tratamento científico.

Para interpretação das informações levantadas, utilizamos a Análise de Conteúdo desenvolvida por Bardin (2011). Segundo a autora, essa técnica pode ser empregada a vários tipos de códigos linguísticos, icônicos ou semióticos, abrangendo, diálogos e comunicações em massa ou em um único grupo. Com esse método é possível estabelecer um esquema de análise que propiciará uma interpretação bem estruturada a partir de categorias que indiquem a sistematização, exploração e diagnóstico dos resultados dos documentos.

A pesquisa foi realizada no Clube de Ciências Prof. Dr. Cristovam W. P. Diniz na Universidade Federal do Pará - Campus de Castanhal, que busca implementar um ambiente de educação não-formal, destinado para o ensino, pesquisa e extensão de ações didáticas voltadas as Ciências e Matemáticas, almejando a popularização da ciência, a iniciação científica infanto-juvenil e a formação de professores (MALHEIRO, 2016).

As atividades do projeto são voltadas para estudantes do 5ㅇ e 60 anos do ensino fundamental, e que residam e estudem na área entorno da universidade onde está localizado o Clube de Ciências. Tal opção de público alvo deu-se em função da carência social e educacional existente na região (ALMEIDA, 2017).

Segundo Almeida (2017), para desenvolver as ações experimentais, assim como acompanhar os alunos durante as atividades do Clube, há voluntários que são denominados de professores-monitores, sendo eles licenciados ou em formação inicial dos cursos de Pedagogia, Ciências Naturais, Biologia, Física, Química e Matemática.

Deste modo, o Clube de Ciências busca com que as crianças discutam conceitos físicos, químicos, biológicos e matemáticos, e com os professoresmonitores procura explorar os conceitos pedagógicos que fundamentam o trabalho experimental investigativo (MALHEIRO, 2016). Ressaltamos que no Clube de Ciências o professor-monitor não deve em nenhum momento comunicar a solução do problema, devendo apenas conduzir perguntas instigantes para direcionar os alunos a encontrarem sozinhos as respostas (ALMEIDA, 2017).

Para se alcançar os objetivos pretendidos, o Clube de Ciências Prof. Dr. Cristovam W. P. Diniz adota a experimentação investigativa como principal metodologia ativa utilizada. Assim, seguindo as etapas propostas por Carvalho et al. (2009), a cada dois sábados uma atividade experimental é desenvolvida. No primeiro dia de encontro efetuam-se os seis primeiros passos, são eles: 1- O professor propõe o problema, 2- Agindo sobre os objetos para ver como eles reagem, 3- Agindo sobre os objetos para obter o efeito desejado, 4- Tomando consciência de como foi produzido o efeito desejado, 5- Dando explicações causais e 6- Escrevendo e desenhando. O segundo sábado é dedicado à sétima e última 
etapa, relacionando atividade e cotidiano, na qual é realizada a contextualização e a sistematização do conhecimento construído no decorrer do experimento.

Na fase do "Escrevendo e Desenhando", o professor-monitor solicita aos estudantes que escrevam e/ou façam um desenho sobre a experiência que realizaram para resolver o problema, podendo ser sugerido que relatem o que fizeram, expliquem por quê o fenômeno aconteceu e o que aprenderam com o experimento (CARVALHO et al., 2009). Diante disso, é perceptível nos registros a construção de ideias, a organização dos conhecimentos, o raciocínio lógico, a reconstrução do experimento de forma articulada, sendo destacados os elementos que foram mais significativos na atividade (SASSERON; CARVALHO, 2010).

Assim, a sequência de ensino analisada seguiu as sete etapas propostas por Carvalho et al. (2009), que foi intitulada "Problema da Água que não Derrama" e explorou as propriedades ligadas à tensão superficial da água. Durante a atividade experimental, os estudantes deveriam solucionar o seguinte problema: Como não derramar a água quando virar o copo de cabeça para baixo?

Para isso, cada grupo deveria manipular os seguintes materiais: água em uma garrafa pet, um copo, uma liga elástica, um pedaço de tecido telado cortado em formato quadrado, pedaços de papel cartão, um palito de dente e uma bacia plástica para evitar que a água derramasse no chão.

Ressaltamos que ao visualizar o tecido telado, os alunos o aproximaram ao pano utilizado em mosquiteiros. Conforme o dicionário Aurélio, este pode ser definido como uma tela, cortina ou rede muito fina que protege ambientes e pessoas contra mosquitos (FERREIRA, 2008).

Para solucionar a problemática proposta, os alunos deveriam encher o copo com água, prendendo o tecido sobre sua parte superior com a liga elástica. Em seguida, o copo deveria ser virado para baixo com o papel cartão sendo segurado sobre o pano para impedir que a água caísse. Ao retirar o papel da "boca" do recipiente a água não cairia, mesmo que um palito de dente fosse colocado dentro do copo através das fibras do tecido.

Ao final das sete fases dessa atividade, os alunos chegaram à conclusão que a água não caiu devido à película formada. Esse conceito foi explanado como sendo oriundo da tensão superficial presente no nível da água acima da "boca" do copo, o que pôde ser observado por todos. A tensão superficial consiste em uma

$$
\begin{aligned}
& \text { propriedade dos líquidos e ocorre devido às forças de atração que as } \\
& \text { moléculas internas do líquido exercem junto às da superfície [...] Esta força } \\
& \text { para o lado e para baixo cria a tensão na superfície, que faz a mesma } \\
& \text { comportar-se como uma película elástica (GOMES; CLAVICO,2005, p. 4-5). }
\end{aligned}
$$

Diante desses aspectos, foram analisados 31 registros desenvolvidos pelos discentes do Clube, durante a etapa "Escrevendo e Desenhando" dessa atividade experimental investigativa. Os registros foram escolhidos a partir do critério de participação dos alunos nos dois sábados em que a sequência de ensino foi aplicada. As produções foram identificadas a partir de cada aluno que a confeccionou, sendo nomeados pela letra maiúscula $A$, acompanhada de números sequenciados para diferenciação, variando de A1 até A31.

Para melhor visualização e interpretação dos registros desenvolvidos, em alguns momentos optamos em transcrever na íntegra os escritos dos discentes, 
sem promover correções ou alterações gramaticais e/ou ortográficas. Destacamos em itálico quaisquer erros na Língua Portuguesa ou uso de coloquialismos, considerando o valor fidedigno das frases, sem modificar seu significado.

Ressaltamos que, ao realizarem a inscrição no Clube de Ciências, os pais ou responsáveis dos estudantes assinam o Termo de Consentimento Livre e Esclarecido (TCLE), autorizando a participação das crianças nas pesquisas realizadas, liberando o uso de suas falas, imagens e produções.

\section{OS INDICADORES DE ALFABETIZAÇÃO CIENTÍFICA EVIDENCIADOS NOS REGISTROS}

Nessa seção, procuramos estabelecer aproximações das discussões teóricas sobre a Alfabetização Científica desenvolvida em sala de aula com o ensino de Ciências propiciado pelo Clube de Ciências Prof. Dr. Cristovam W. P. Diniz. Para tanto, usamos os indicadores de Alfabetização Científica de Sasseron (2008) e Sasseron e Carvalho (2010) para analisar os registros gráficos e escritos desenvolvidos pelos estudantes do Clube de Ciências durante a etapa do escrevendo e desenhando da atividade experimental investigativa "Problema da Água que não Derrama".

Nesse contexto, os registros foram categorizados conforme a linguagem utilizada na exposição das ideias, encontrando três categorias: Desenho, Escrita, Escrita e desenho. Foram encontrados indicadores em todos os registros analisados, sendo que 7 deles possuíam somente desenhos, 1 com apenas escrita e 23 com a articulação entre desenho e escrita.

\section{Categoria Desenho}

Concebemos que os desenhos são elementos que favorecem a construção do conhecimento, uma vez que, ao desenvolver a prática de desenhar, o aluno também explora sua criatividade, entendimento e concepção de Ciência, bem como contribui para elaborar explicações, construir o raciocínio, entre outras habilidades (CAPELLE e MUNFORD, 2015).

Assim, dentre os 7 estudantes que utilizaram apenas o desenho como forma de expressar suas percepções sobre a atividade desenvolvida, evidenciamos que, em sua maioria, apresentam os materiais utilizados no experimento por meio da ilustração dos objetos, acompanhados ou não de legendas.

Entendemos que o uso de legendas não se configura em escritos completos, uma vez que elas são utilizadas somente para nomear os materiais, sem apresentar quaisquer informações adicionais que pudessem expressar os caminhos percorridos e os resultados encontrados.

Encontramos 5 desenhos que expressaram o indicador seriação de informações, pois procuram somente listar os dados utilizados para solução da problemática proposta (SASSERON, 2008). Destacamos na Figura 2 um exemplo desse indicador a partir do registro do aluno A1. 
Figura 2 - Registro do aluno A1

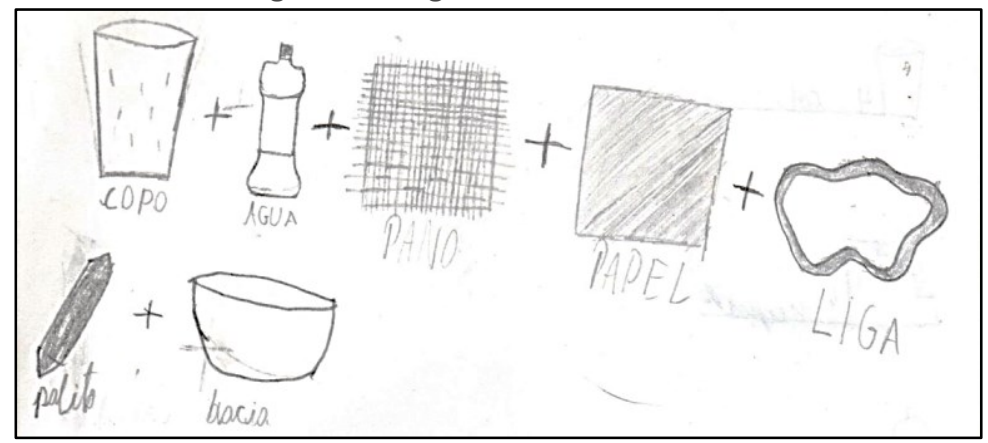

Fonte: Dados da pesquisa (2018).

Notamos que em seu desenho A1 mostra os materiais utilizados na experimentação, em que aparecem legendas denominando cada material. Deste modo, percebemos a seriação de informações, pois o aluno demonstra claramente os objetos que foram distribuídos na primeira fase da atividade para a resolução do problema (SASSERON; CARVALHO, 2010).

Como A1 não acrescenta nenhuma outra informação, além do desenho com legenda, compreendemos que o aparato experimental foi o que mais chamou a atenção do discente, despertando nele o interesse em destacá-lo. Segundo Carvalho et al. (2009), não é esperado que os estudantes relatem tudo o que ocorreu na atividade, já que a proposta é que os discentes estejam livres para escrever e desenhar sobre suas descobertas.

Malheiro (2016, p. 120) também enfatiza não ser possível "esperar que todos os estudantes consigam construir um texto completo, com todos os aspectos relatados, pois muitas vezes ressaltam apenas o que mais chamou atenção no experimento. Isso pode também ser percebido no desenho".

Apesar da maioria dos alunos que utilizaram o desenho como recurso linguístico destacar somente os materiais utilizados no momento experimental, 2 discentes também escolheram explorar outras etapas da atividade, como a indicação da manipulação dos objetos e as hipóteses levantadas para a solução do problema. Desta maneira, a Figura 3 apresenta o registro do aluno A6 em que é possível verificar vários indicadores de Alfabetização Científica.

Figura 3-Registro do aluno A6

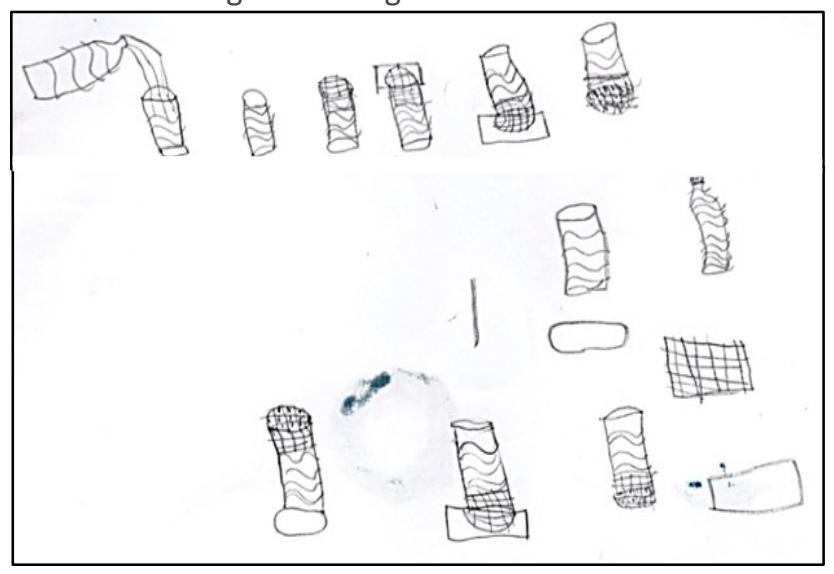

Fonte: Dados da pesquisa (2018). 
Podemos observar que no lado inferior direito do registro, A6 destaca os materiais que utilizou na experimentação, são eles: garrafa pet, copo, água dentro dos recipientes, tecido telado, papel cartão, liga elástica e palito de dente. Com isso, o aluno realiza a seriação de informações, uma vez que relaciona os dados com os quais trabalhou (SASSERON; CARVALHO, 2010).

Na parte superior do desenho, o estudante indica detalhadamente os passos seguidos para a resolução do problema, demonstrando que primeiramente era necessário colocar a água no copo, cobri-lo com o tecido telado prezo com a fita, na sequência acrescentar o papel cartão, para virar copo e finalmente remover o papel cartão para que a água não caísse. Com isso, A6 demonstra a organização de informações obtidas durante a atividade investigativa, pois procura preparar os dados existentes sobre a problemática proposta (SASSERON, 2008).

Apesar de não haver nada escrito o aluno conseguiu apresentar também o raciocínio lógico, uma vez que este indicador compreende "o modo como as ideias são desenvolvidas e apresentadas. Relaciona-se, pois, diretamente com a forma como o pensamento é exposto" (SASSERON, 2008, p. 67). Além disso, A6 faz uso do raciocínio proporcional, já que expõe o modo como seu pensamento foi estruturado para solucionar o problema, destacando os modos como variáveis estão associadas entre si, ilustrando a interdependência entre elas.

A partir dos registros desenvolvidos nesta categoria, entendemos que o desenho consiste em "um trabalho gráfico que a criança elabora, não como resultado de uma cópia, mas da construção e da interpretação que ela faz dos objetos, dentro de seu contexto específico" (MORAES; CARVALHO, 2017, p. 954). Portanto, o ato de desenhar é um elemento importante para a Alfabetização Científica, pois possibilita a estruturação de informações de modo diferenciado da escrita que muitas vezes facilita a apresentação e compreensão de ideias.

\section{Categoria Escrita}

Na categoria escrita encontramos somente um registro em que a aluna A8 construiu um pequeno texto no qual primeiramente apresenta os materiais utilizados e depois descreve o passo a passo de como realizou o experimento. A Figura 4 expõe as colocações da discente.

Figura 4 - Registro do aluno A8

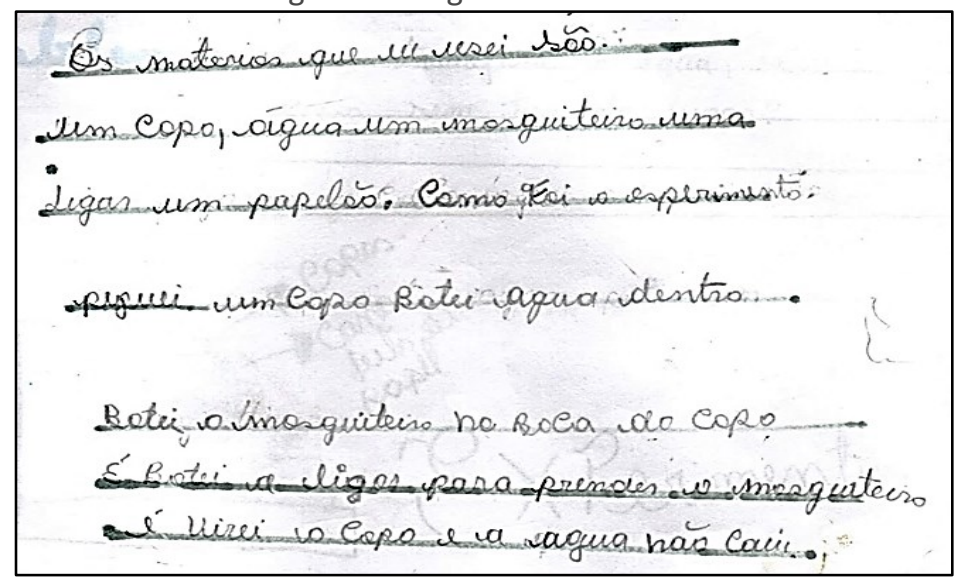

Fonte: Dados da pesquisa (2018). 
Quando A8 escreve: "Os materiais que eu usei são: um copo, água um mosquiteiro uma liga um papelão", compreendemos que a discente demonstrou a seriação das informações, pois seu texto descreve os objetos que foram utilizados para resolver o problema proposto (SASSERON, 2008).

Após apresentar os materiais, A8 narra: "Como foi o experimento: peguei um copo botei agua dentro. Botei o mosquiteiro na boca do copo é botei a liga para prender o mosquiteiro é virei o copo e agua não caiu". Com isso, ela desenvolveu a organização das informações, pois organiza os dados existentes para então expor seu pensamento de como desenvolveu a experimentação, apresentando, também, o raciocínio lógico (SASSERON, 2008).

Notamos, ainda, que a aluna utiliza nomenclaturas próprias de seu contexto diário de convivência, "essa relação experimento-cotidiano é fundamental para a valorização da diversidade de experiências que cada um dos estudantes traz para a sala de aula" (MALHEIRO, 2016, p. 121).

Apesar da discente não trazer uma explicação sobre o fenômeno ocorrido, ela conseguiu relatar de maneira simples e direta as ideias que lhe foram mais relevantes, o que demonstra um entendimento sobre situações exploradas no experimento. É necessário considerar que os alunos "podem não dar explicações completas ou mesmo não dar qualquer explicação, sem que isso signifique que não tenham compreendido" (CARVALHO et al., 2009, p. 43).

Partindo da percepção do registro de A8, consideramos que "a escrita, como instrumento cognitivo, tende a ser uma ferramenta discursiva importante por organizar e consolidar ideias rudimentares em conhecimento mais coerente e bem estruturado" (OLIVEIRA; CARVALHO, 2005, p. 349). Deste modo, esse recurso semiótico se configura como uma importante ferramenta para a Alfabetização Científica já que favorece a exposição organizada dos pensamentos.

\section{Categoria Escrita e Desenho}

As produções da categoria escrita e desenho foram mais completas com relação à exposição de informações, pois as crianças buscaram reconstruir o que aconteceu na atividade, apresentaram o problema, descreveram os materiais, mostraram como fizeram o experimento e deram explicações das causas do fenômeno que ocorreu na experimentação.

Desta maneira, observamos que os 21 registros apresentam os indicadores de seriação, organização e classificação de informações, assim como o raciocínio lógico e proporcional, justificativa, previsão e explicação (SASSERON, 2008).

Assim, o primeiro registro que selecionamos para representar esta categoria está exposto na Figura 5 e pertence ao aluno A9. 
Figura 5 - Registro do aluno A9

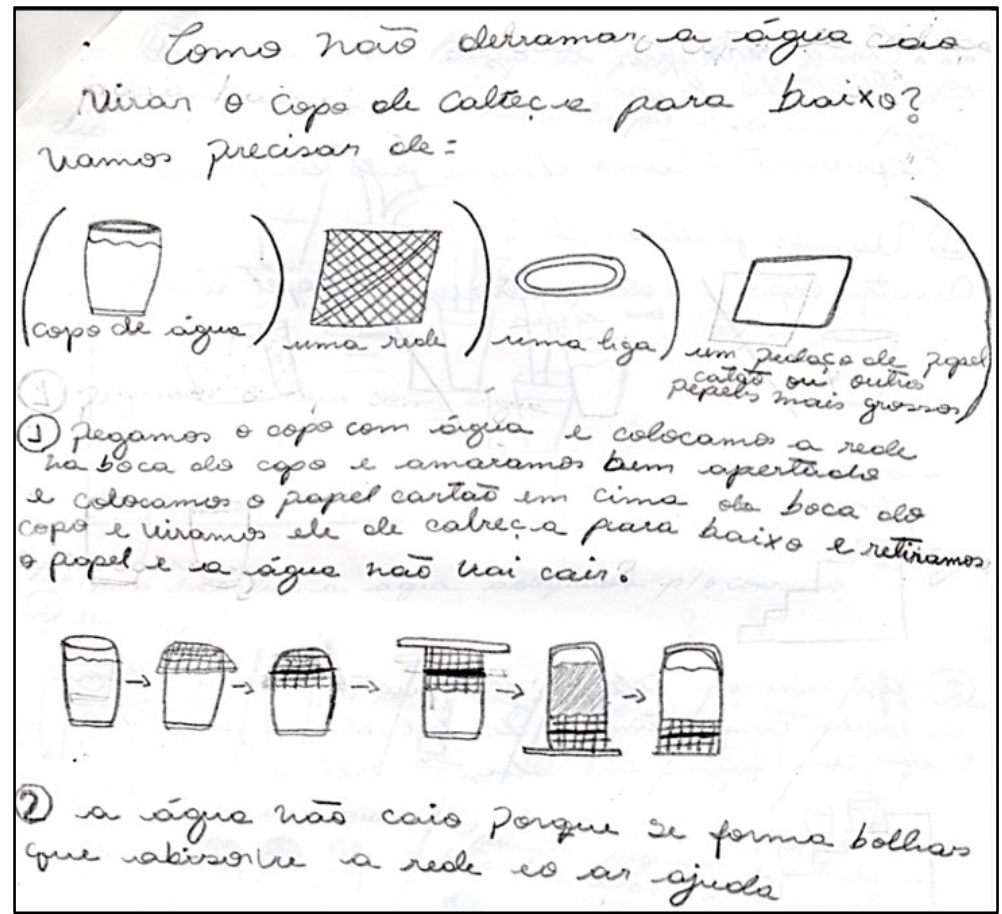

Fonte: Dados da pesquisa (2018).

Primeiramente A9 apresenta a problemática da atividade e, em seguida, lista por meio de desenhos legendados os materiais usados para solucionar o respectivo problema. Desta maneira, notamos que o discente demostra a seriação de informações (SASSERON, 2008).

A organização de informações surge quando A9 descreve como realizou o experimento fazendo uso de um pequeno texto seguido da ilustração de cada etapa efetuada. Além disso, notamos que o aluno estrutura sua produção por meio dos itens números (1) e (2), demonstrando a classificação das informações, uma vez que ele procura ordenar os elementos que estão sendo expostos em seu registro (SASSERON; CARVALHO, 2010).

Esse cuidado de A9 em estruturar sua produção de maneira coesa e internamente coerente, indica que ele fez uso do raciocínio lógico e do raciocínio proporcional na construção de seu texto. Além disso, quando o discente utiliza no final do item (1) a expressão "[...] e a água não vai cair", ele deixa explícito a previsão de que ao se seguir todos os passos indicados, é certo que o líquido não será derramado. Para Carvalho et al. (2009), esse processo de exposição de ideias utilizado por A9 é representado pela capacidade de o aluno recriar e relacionar os passos seguidos para responder ao problema.

No item (2), percebemos uma explicação para o fenômeno quando o estudante cita que "a água não caio porque se formam bolhas que absorve a rede eo ar ajuda". Apesar de ele não utilizar o termo tensão superficial em seus escritos, notamos que indica compreender minimamente o conceito científico.

De acordo com Carvalho et al. (2009) e Malheiro (2016), os discentes podem dar indícios de explicações próximas daquilo que mais chamou sua atenção, ou seja, não deve esperar que seja relatado tudo exatamente como foi feito e 
discutido nas etapas da experimentação investigativa, já que a proposta é que os estudantes estejam livres para escrever e desenhar sobre suas descobertas.

A partir da análise desse registro, comprovamos a importância da integração das duas formas de linguagens (escrita e desenho), pois uma complementa a outra para que o aluno possa organizar e melhor expor suas ideias. Para Capelle e Munford (2015), a associação desses estilos linguísticos pode contribuir significativamente para a formação e construção do conhecimento, ocasionando a aprendizagem de conceitos.

Acerca dessa relação de integração entre escrever e desenhar, destacamos na Figura 6 o registro produzido pela aluna A13, em que primeiramente apresenta suas ideias com um texto e depois acrescenta desenhos para completar suas colocações.

Figura 6 - Registro do aluno A13

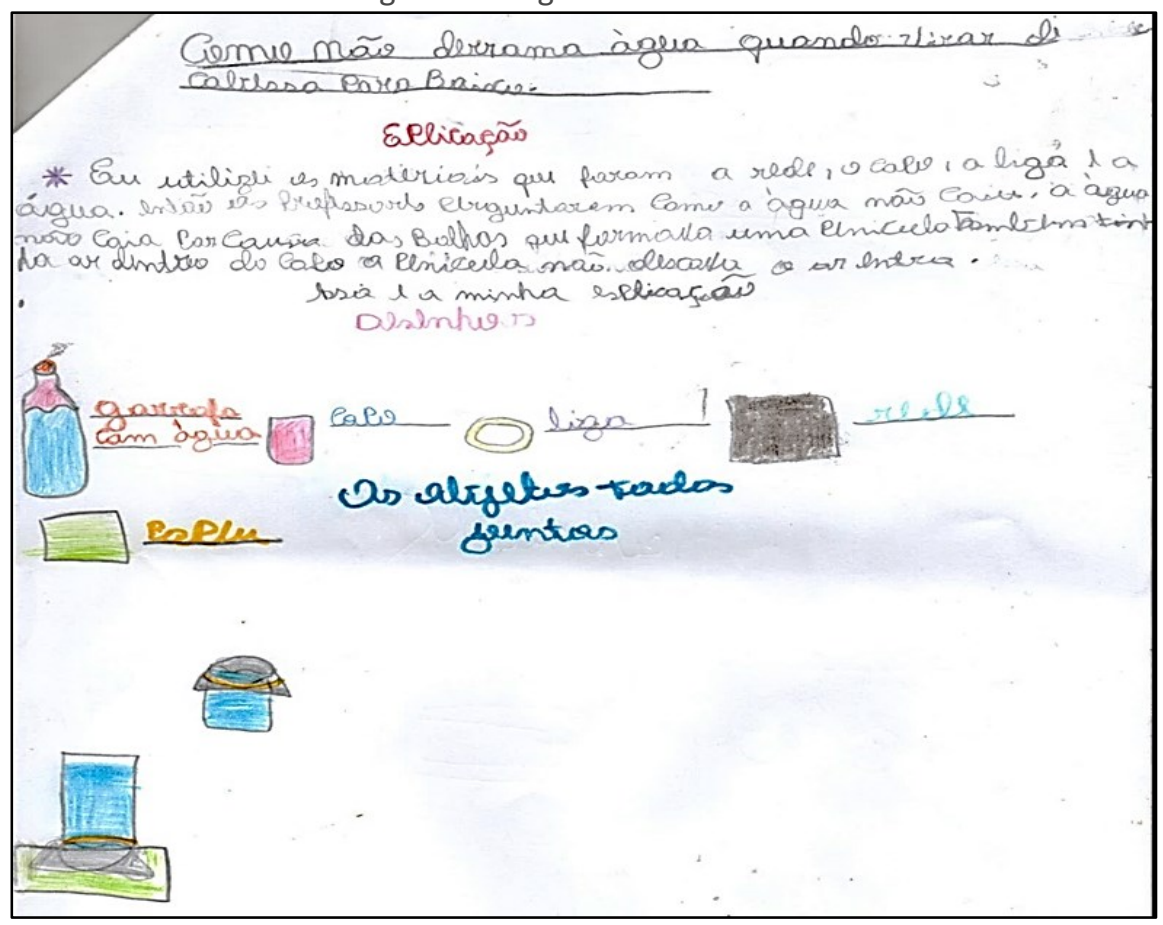

Fonte: Dados da pesquisa (2018).

Notamos que esse registro é dividido em quatro partes, ocorrendo a classificação de informações da seguinte forma: Primeiramente a criança apresenta o problema proposto na atividade. Na segunda parte, intitulada "Eplicação", A13 indica os materiais, reapresenta a problemática que foi enfatizada pelos professores-monitores, e explica por que a água não caiu. $\mathrm{Na}$ seção "Desenhos" estão os materiais desenhados com suas respectivas legendas. Já na quarta e última parte do registro, encontramos a denominação de "os objetos todos juntos", na qual demonstra como efetivou a experiência.

Na parte em que A13 escreve sobre o que concebe como explicação para o experimento, ela inicialmente elenca os objetos utilizados: "Eu utilizei os materiais que foram a rede, o copo, a liga e água". Essa ideia é complementada pelos desenhos com legendas expostos logo abaixo, em que a aluna acrescenta novos 
Na sequência, a discente destaca que "então os professores perguntaram como a água não caiu". Entendemos que quando o professor almeja trabalhar a Alfabetização Científica, o mesmo deverá estimular em seus alunos diversas habilidades, possibilitando-os a construírem respostas consistentes para explicar e/ou solucionar problemas (SASSERON, 2008).

Logo após A13 traz a explicação dos acontecimentos ocorridos: "a água não caia por causa das bolhas que formava uma penicula de ar dentro do copo a penicula não dexava o ar entra". Novamente notamos que, apesar de sua dificuldade na escrita e concordância, a aluna elucida o conceito científico tensão superficial, aparecendo por meio do termo "película", indicando que esse vocábulo foi o que mais chamou a atenção durante a conceitualização do experimento.

Ao argumentar de maneira coerente sobre as causas do porque a água não caiu, destacando os elementos que representam o fenômeno tanto de maneira escrita quanto em forma de desenho, identificamos a demonstração dos indicadores organização das informações e raciocínio lógico (SASSERON, 2008).

$\mathrm{Na}$ Figura 7, a seguir, apresentamos o registro do aluno A17 que faz uso de desenhos e escritos para explanar sobre suas descobertas. Além disso, o discente intitula seu texto pelo termo "tensão superficial", que consiste no conceito central abordado com a atividade experimental.

Figura 7 - Registro do aluno A17

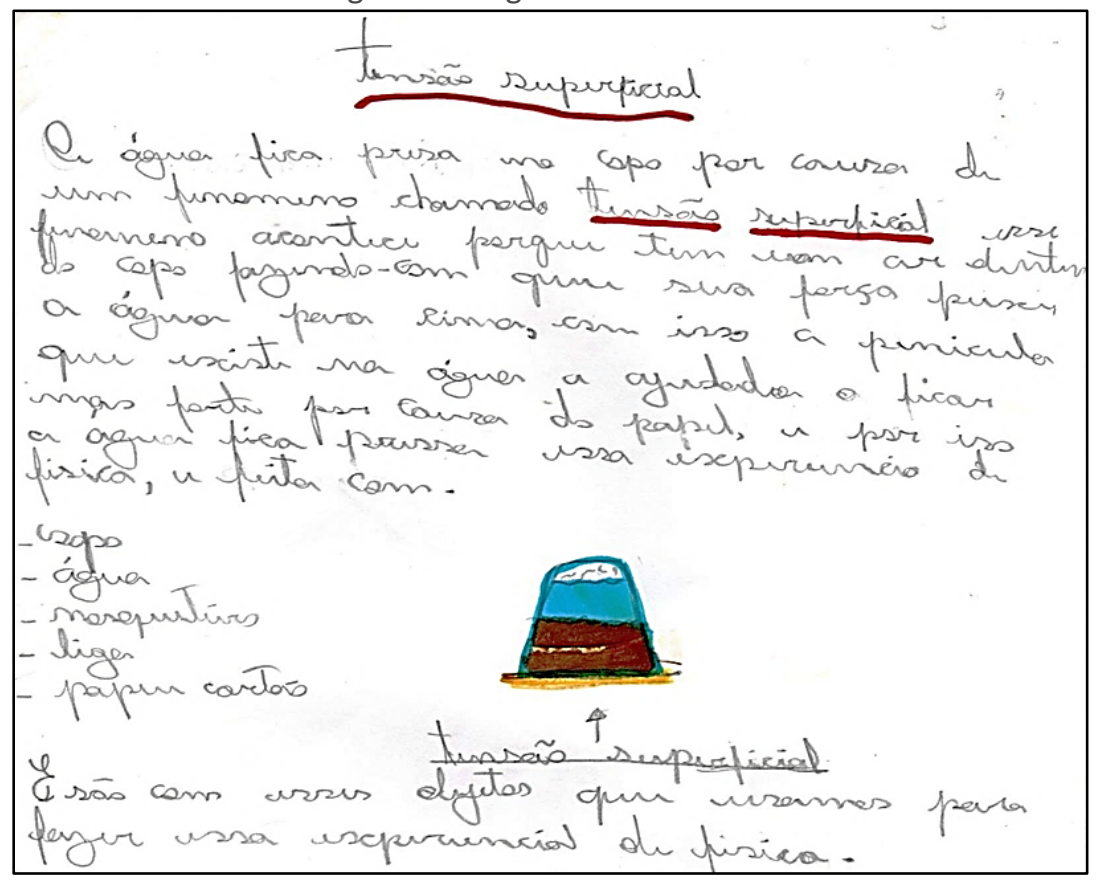

Fonte: Dados da pesquisa (2018).

A17 inicia afirmando que "a água fica presa no copo por causa de um fenomeno chamado tensão superficial esse fenomeno acontece porque tem um ar dentro do copo fazendo com que sua força puxe a água para cima, com isso a penicula que existe na água a ajudada a ficar mais forte por causa do papel, e por isso a água fica pressa".

Notamos que o estudante possui uma linguagem própria para tecer uma explicação de como e porque o fenômeno acontece, além de enfatizar as 
particularidades das suas ações, apresentando um raciocínio lógico para expressar de maneira coerente suas ideias e compreensões (SASSERON; CARVALHO, 2010).

Em seguida, no intuito de estabelecer a organização de informações, A17 descreve os materiais que utilizou na atividade. Depois, o aluno afirma que "são com esses objetos que usaremos para fazer essa experiencia de fisica", estabelecendo uma relação de interdependência entre os instrumentos e o experimento realizado, demonstrando o uso do raciocínio proporcional.

Ao longo de todo o registro, o discente grifa o termo tensão superficial na busca de chamar atenção para o conceito envolvido. Com isso, a temática se torna parte central da produção, sendo estabelecidas relações causais entre os elementos do problema e as etapas que levaram a sua solução. O uso desse recurso indica a busca por uma justificativa que sirva como garantia para o que está sendo exposto (SASSERON, 2008).

O desenho feito por A17 sintetiza todas as ideias apresentadas no texto, uma vez que demonstra um copo com água de cabeça para baixo, as bolhas de ar dentro do copo e o papel cartão. Desta maneira, entendemos que as representações gráficas são elementos importantes nas atividades científicas, pois complementam a apresentação e compreensão de informações expostas nos escritos (CAPELLE; MUNFORD, 2015).

No próximo registro o aluno evidenciou uma compreensão para além da escrita, desenho e explicação. A12 inicia seu registro destacando também um dos termos que foi trabalhado na atividade experimental "tensão superficial".

Figura 8 - Registro do aluno A21

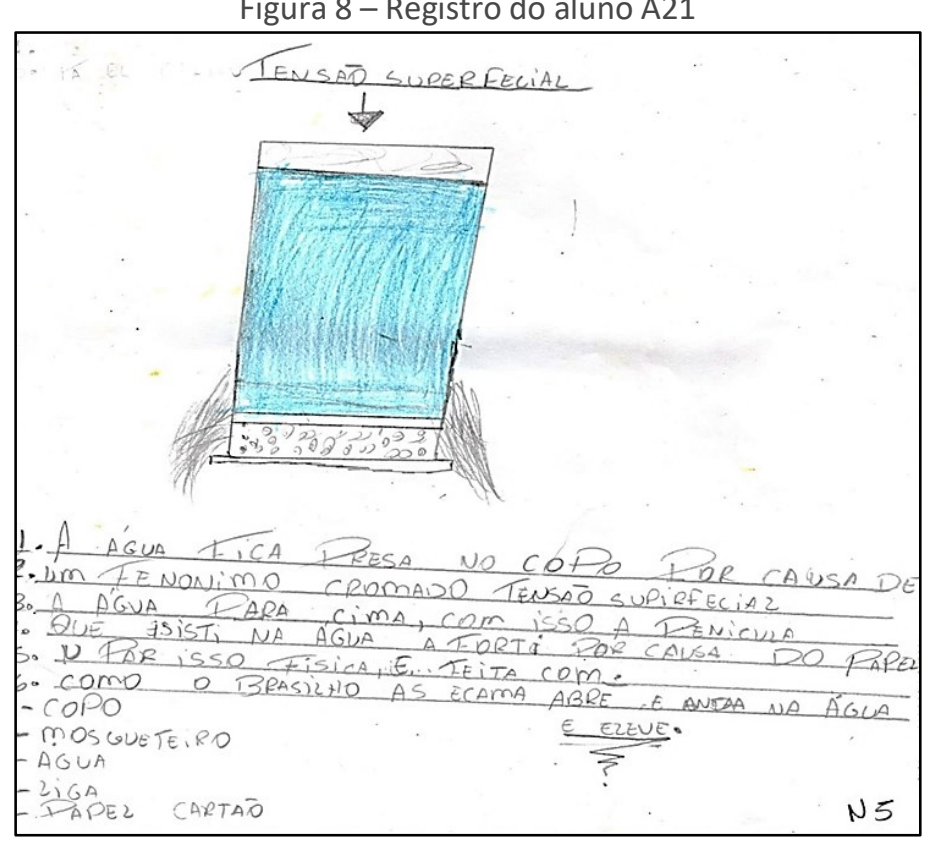

Fonte: Dados da pesquisa (2018).

Nesse registro identificamos que o estudante consegue expor como e por que o procedimento experimental foi realizado. Para estabelecer essa explicação, A21 faz uso de duas formas de linguagem, em que primeiramente usa o desenho para ilustrar como os materiais deveriam estar organizados para que a água caísse e gerasse a tensão superficial. 
Em seguida, ele usa a escrita para descrever a forma como o fenômeno ocorre, expondo como suas ideias foram estruturadas. A partir disso, notamos que A21 demonstrou ter utilizado o raciocínio lógico e raciocínio proporcional na construção da compreensão sobre o fato. Por fim, escreveu os materiais que usou na atividade indicando a organização de informações (SASSERON, 2008; SASSERON; CARVALHO, 2010).

Em suas anotações o aluno ainda faz um comentário relevante, afirmando que o lagarto basilisco consegue andar sobre a água devido a tensão superficial. O referido réptil é conhecido cientificamente por Basiliscus basiliscus, e possui a habilidade de correr sobre a água devido a anatomia de suas patas traseiras que possuem dedos bem alongados e unidos uns aos outros por membranas de pele, facilitando a distribuição de seu peso (FERREIRA, 2008).

Com isso, notamos que A21 atinge a abordagem do problema em outras circunstâncias, na qual sua preocupação não se resume a identificar em que ocasiões o conceito é visto no cotidiano, mais também em complementar a ideia explicando de que maneira isso ocorre, como no caso do lagarto que utiliza as membranas de suas patas para poder andar sobre a água.

Nesse aspecto, percebemos que a atividade experimental desenvolvida no Clube de Ciências propiciou que esse aluno ultrapassasse a simples manipulação dos materiais, e que fosse levado "a compreender o fenômeno que ele teve a oportunidade de vivenciar e a criar novos significados para explicar o mundo ao seu redor" (CARVALHO et al., 2009, p. 40).

Segundo Carvalho et al. (2009, p. 14), as atividades experimentais "dão aos alunos oportunidade de levantar suas próprias hipóteses e testá-las, criando condições para que essas ideias sejam discutidas em grupo". Essas discussões são mediadas pelos professores-monitores, que contribuem de forma significativa para que os alunos cheguem às soluções, sem dar as respostas, mas indagando e estimulando a sua curiosidade.

Além disso, todos os registros apresentados mostram como os alunos constroem o conhecimento, demonstrando coesão e coerência nas exposições sobre as informações, explicações e aproximações com o cotidiano em relação ao problema proposto, indicando que os estudantes estão engajados no processo de Alfabetização Científica (SASSERON; CARVALHO, 2010).

\section{CONSIDERAÇÕES FINAIS}

A partir dos indicadores de Alfabetização Científica identificados, conseguimos compreender como as crianças constroem e expõem o conhecimento, explorando o problema proposto, os materiais utilizados, a organização e raciocínio de ideias a cada etapa da atividade, bem como as explicações a aproximações com cotidiano do fenômeno envolvido no experimento.

$\mathrm{Na}$ categoria desenho percebemos que os discentes não apresentaram o problema nem deram explicações dos resultados da experimentação. Mas, seus registros forneceram informações obtidas durante a atividade experimental que indicavam a seriação e organização de informações, bem como o raciocínio lógico 
e proporcional. Estes indicadores definem o início da construção das ideias pela qual podem se estabelecer novos conhecimentos e a Alfabetização Científica.

Já na categoria escrita, A8 construiu um texto em que relata todas as fases da sequência experimental, em que percebemos a seriação e organização de informações, além do raciocínio lógico. Com isso, verificamos que o discente procurou destacar o que julgou mais relevante.

$\mathrm{Na}$ categoria em que os alunos utilizaram a escrita juntamente com o desenho ficou evidente uma maior frequência de indicadores de Alfabetização Científica, sendo manifestados a seriação, organização e classificação de informações, assim como o raciocínio lógico e proporcional, justificativa, previsão e explicação. Isso comprova que esses elementos linguísticos são mais proveitosos quando são utilizados em consonância um com o outro, especialmente para estudantes já alfabetizados.

Destacamos que em nenhuma das categorias analisadas foram observados os indicadores levantamento e teste de hipóteses, processo que acontece nas etapas de manipulação dos objetos. Compreendemos que esse fato ocorreu em função dos alunos expressarem em seus registros somente o que mais lhes chamou a atenção, demarcando que eles optaram em relatar apenas os resultados e conclusões obtidos a partir da busca por suposições e provas acerca do experimento.

Contudo, a não existência dessas categorias podem indicar uma falha no desenvolvimento da etapa escrevendo e desenhando, mostrando que poderiam ser feitas adaptações que possibilitassem o melhor envolvimento dos alunos para a elaboração de seus escritos ao longo de todas as fases da atividade experimental.

A partir de uma maneira própria de discurso, cada discente teve a capacidade de produzir seu relato com base na sua compreensão em relação ao fenômeno estudado. Contudo, isso só foi possível devido ao empenho dos professoresmonitores que mediaram as ações e discussões das etapas da sequência de ensino investigativo de maneira organizada e competente, colaborando para construção das ideias. Logo, foi importante a visualização de um percurso que pode contribuir para a Alfabetização Científica desenvolvida por meio de atividades experimentais no Clube de Ciências investigado, em que sua metodologia propicia a observação dos indicadores presentes nos escritos e desenhos dos alunos.

Apesar de predominar o discurso escrito no ensino e aprendizagem de conceitos científicos, consideramos relevante que se abram novas possibilidades para os estudantes transmitirem o que aprenderam sobre um determinado assunto. Nesse aspecto, os desenhos podem possibilitar a exposição de ideias que muitas vezes não conseguem ser ditas somente com a escrita.

Portanto, compreendemos que as duas formas de linguagem colaboram para que estudantes consigam compreender e discutir a Ciência de maneira consciente e reflexiva, engajando-os no processo de Alfabetização Científica. 


\title{
Drawing and writing as elements for the development of scientific literacy: analysis of the productions of the students of a science club
}

\begin{abstract}
This study aims to analyze the indicators of Scientific Literacy evidenced in the productions of drawing and writing developed by students of the Science Club Prof. Dr. Cristovam W. P. Diniz, during an experimental investigative activity. The research is based on a qualitative approach, using Content Analysis for the interpretation of 31 productions. The space analyzed is considered a non-formal environment destined to the teaching, research and extension of didactic actions directed to Sciences and Mathematics. The applied experimental investigative activity was titled "Non-Pouring Water Problem" and explored the properties attached to the surface tension of the water. From the analysis of the records, we can understand how students construct and expose the scientific knowledge involved in the sequence of investigative teaching, exploring the proposed problem, the materials used, the organization and reasoning of ideas at each stage of the activity, as well as the explanations to everyday approximations of the phenomenon involved in the experiment. The indicators of Scientific Literacy evidenced were the serialization, organization and classification of information as well as the logic and proportional reasoning, justification, prediction and explanation. Thus, we understand that the two forms of language collaborate so that students are able to understand and discuss science in a conscious and reflective way, engaging them in the process of Scientific Literacy.
\end{abstract}

KEYWORDS: Scientific Literacy. Writing. Drawing. Science Club. 


\section{REFERÊNCIAS}

ALMEIDA, W. N. C. A Argumentação e a Experimentação Investigativa no Ensino de Matemática: O Problema das Formas em um Clube de Ciências. 2017. 109 f. Dissertação de Mestrado em Docência em Educação em Ciências e Matemáticas Programa de Pós-Graduação em Docência em Educação em Ciências e Matemáticas, Instituto de Educação Matemática e Científica, Universidade Federal do Pará, Belém, 2017. Disponível em: http://repositorio.ufpa.br/jspui/bitstream/2011/10520/1/Dissertacao_Argument acaoExperimentacaolnvestigativa.pdf . Acesso em: 10 mai. 2019.

BARDIN, L. Análise de Conteúdo. 1 ed., 3. reimp. São Paulo: Edições 70, 2011.

BUCH, G. M.; SCHROEDER, E. Clubes de ciências e alfabetização científica: concepções dos professores coordenadores da rede municipal de ensino de Blumenau (SC). Experiências em Ensino de Ciências, Cuiabá, v. 8, n. 01, p. 56-70, 2013. Disponível em:

https://if.ufmt.br/eenci/artigos/Artigo_ID199/v8_n1_a2013.pdf. Acesso em: 20 dez. 2019.

CAPPELLE, V.; MUNFORD, D. Desenhando e Escrevendo para Aprender Ciências nos Anos Iniciais do Ensino Fundamental. Universidade Federal de Minas Gerais. Alexandria: Revista de Educação em Ciência e Tecnologia, v. 8, n. 2, p. 123-142, 2015. Disponível em:

https://periodicos.ufsc.br/index.php/alexandria/article/view/19825153.2015v8n2p123/29499. Acesso em: 22 dez. 2019.

CARVALHO, A. M. P.; VANNUCCHI, A. I.; BARROS, M. A.; GONÇALVES, M. E. R.; REY, R. C. Ciências no ensino fundamental: o conhecimento físico. 2a ed. São Paulo: Scipione, 2009.

CHASSOT, A. Alfabetização científica: uma possibilidade para a inclusão social. Revista Brasileira de Educação, n. 22, p. 89-100, 2003. Disponível em: https://doi.org/10.1590/S1413-24782003000100009. Acesso em: 20 jul. 2020.

CUNHA, R. B. Alfabetização Científica ou Letramento Científico?:interesses envolvidos nas interpretações da noção de scientific literacy. Revista Brasileira de Educação, v. 22, n. 68, 2017. Disponível em: https://www.scielo.br/pdf/rbedu/v22n68/1413-2478-rbedu-22-68-0169.pdf. Acesso em: 20 jul. 2020.

CUNHA, R. B. O que significa alfabetização ou letramento para os pesquisadores da educação científica e qual o impacto desses conceitos no ensino de ciências.

Ciência \& Educação, v. 24, n. 1, 2018. Disponível em: https://www.scielo.br/pdf/ciedu/v24n1/1516-7313-ciedu-24-01-0027.pdf. Acesso em: 20 jul. 2020.

FERREIRA, A. B. H. Dicionário Aurélio Ilustrado. 1 ed. Curitiba: Editora Positivo, 2008. 
FERREIRA, L. D. A importância do desenho na alfabetização de crianças. In: Encontro Científico e Simpósio de Educação Unisalesiano, V; 2015, Bauru. Anais... Bauru-SP: Unesp, 2015.

GOHN, M. G. Educação não formal e cultura política: Impactos sobre o associativo do terceiro setor. 2 ed. São Paulo: Cortez, 2001.

GOMES, A. S.; CLAVICO, E. Propriedades físico-químicas da água. Rio de Janeiro: Departamento de Biologia Marinha. Universidade Federal Fluminense, 2005.

GONZAGA, A. T.; SOUZA, A. C. L.; BRITO, R. G.; OLIVEIRA, C. B.; COSTA, M. O. Os espaços não formais em cena: uma carta àqueles que defendem a educação em ciências e a Amazônia. ACTIO, Curitiba, v. 4, n. 3, p. 327-345, set./dez. 2019.

Disponível em: https://periodicos.utfpr.edu.br/actio/article/view/10595. Acesso em: 20 jul. 2020.

KUNDLATSCH, A.; SILVA, C. S. Análise da contribuição do desenho de estudantes sobre elementos químicos para o processo de ensino-aprendizagem. Encontro Nacional de Ensino de Química, XVIII; 2016, Florianópolis. Anais... FlorianópolisSC: UFSC, 2016.

MALHEIRO, J. M. S. Atividades experimentais no ensino de ciências: limites e possibilidades. ACTIO, Curitiba, v. 1, n. 1, p. 107-126, jul./dez., 2016. Disponível em: https://periodicos.utfpr.edu.br/actio/article/view/4796/3150. Acesso em: 11 mar. 2019.

MORAES, T. S. V.; CARVALHO, A. M. P. Investigação científica para o 1o ano do ensino fundamental: uma articulação entre falas e representações gráficas dos alunos. Ciência \& Educação, v. 23, n. 4, p.941-961, 2017. Disponível em: http://www.scielo.br/pdf/ciedu/v23n4/1516-7313-ciedu-23-04-0941.pdf. Acesso em: 20 out. 2019.

OLIVEIRA, C. M. A.; CARVALHO, A. M. P. Escrevendo em aulas de Ciências. Ciência e Educação, v. 11, n. 3, p. 347-366, 2005. Disponível em:

http://www.scielo.br/pdf/ciedu/v11n3/01.pdf. Acesso em: 20 out. 2019.

OLIVEIRA, M. M. Como fazer pesquisa qualitativa. 6 ed. Petrópolis - RJ: Vozes, 2014.

PRÁ, G.; TOMIO, D. Clube de Ciências: Condições de Produção da Pesquisa em Educação Científica no Brasil. Alexandria, Florianópolis, v. 7, p. 179-207, 2014. Disponível em: https://periodicos.ufsc.br/index.php/alexandria/article/view/38208/29112. Acesso em: 22 dez. 2019.

SASSERON, L. H. Alfabetização Científica no Ensino Fundamental: Estrutura e Indicadores deste processo em sala de aula. 2008. 281 f. Tese (Doutorado no Ensino de Ciências e Matemática). Faculdade de Educação da Universidade de São Paulo, USP, São Paulo, 2008. 
SASSERON, L. H.; CARVALHO, A. M. P. Escrita e Desenho: Análise das Interações Presentes nos Registros Elaborados por Alunos do Ensino Fundamental. Revista Brasileira de Pesquisa em Educação em Ciências, v. 10, n. 2, 2010. Disponível em: https://periodicos.ufmg.br/index.php/rbpec/article/view/3977/2541. Acesso em: 19 dez. 2019.

SASSERON, L. H.; CARVALHO, A. M. P. Alfabetização Científica: Uma Revisão Bibliográfica. Investigações em Ensino de Ciências, v. 16, n. 1, p. 59-77, 2011. Disponível em:

https://www.if.ufrgs.br/cref/ojs/index.php/ienci/article/view/246/172. Acesso em: 19 dez. 2019.

SOARES, M. Alfabetização e Letramento: Caminhos e Descaminhos. In: Revista Pátio - Revista Pedagógica. Porto Alegre/RS: Artmed Editora, p. 96-100, 2004.

TOMIO, D.; HERMANN, A. P. Mapeamento dos Clubes de Ciências da América Latina e Construção do Site da Rede Internacional de Clubes de Ciências. Revista Ensaio, Belo Horizonte, v. 21, e10483, 2019. Disponível em:

http://www.scielo.br/pdf/epec/v21/1983-2117-epec-21-e10483.pdf. Acesso em: 22 dez. 2019.

Recebido: 12 mar. 2020

Aprovado: 18 ago. 2020

DOI: 10.3895/actio.v5n3.11766

Como citar:

ALMEIDA, W. N. C.; AMORIM, J. L. de.; MALHEIRO, J. M. da S. O desenho e a escrita como elementos para o desenvolvimento da alfabetização científica: análise das produções dos estudantes de um clube de Ciências. ACTIO, Curitiba, v. 5, n. 3, p. 1-23, set./dez. 2020. Disponível em

$<$ https://periodicos.utfpr.edu.br/actio>. Acesso em: XXX

Correspondência:

Willa Nayana Corrêa Almeida

Avenida dos Universitários, Jaderlândia, Castanhal, Pará, Brasil.

Direito autoral: Este artigo está licenciado sob os termos da Licença Creative Commons-Atribuição 4.0 Internacional.

\section{(c) (1)}

